\title{
The Application of Schema Theory in Teaching College English Writing
}

\author{
Fushan Sun \\ Qingdao University of Science and Technology, Qingdao, China
}

\begin{abstract}
Improving English writing ability is always a difficult task confronted by Chinese teachers and students. In this essay, the author presents the results of an empirical study, which verify the application of Schema Theory is effective in improving Chinese students' English writing competence.
\end{abstract}

\section{Index Terms - Schema Theory, English writing, activate schemata}

\section{INTRODUCTION}

Writing has always been viewed as a significant skill in studying English, since it involves a process of selecting, combining, and arranging individual words to develop ideas. Containing such a complex process, a qualified essay is an organic organization of words, form and content. Host of teachers have spent much time and energy in teaching English writing, while many none-English majors still fail to accomplish satisfying English compositions.

In China, improving students' writing ability is one of the most significant tasks for English teachers, who have done lots of research in this field. Currently, much research has been carried out to study second language writing. Wang Wenyu and Wang Lifei have conducted research on second language learning in 2004. In the past 10 years, the studies on second language mostly concentrate on the following fields: native thinking patterns and second language writing, native thinking patterns and their relationship with second language competence, language features of second language essays, the factors influencing second language competence, second language teaching, testing of second language writing. Wang Wenyu and Wang Lifei (2004) have pointed out that finding out a good way to teaching English writing is crucial. Yao Lan and Cheng Lini drew a similar conclusion on second language research in 2005. They claimed that the number of empirical studies based on qualitative and quantitative analysis had been rising, but empirical studies on college English writing is not sufficient. When it comes to the research on English writing teaching, much of it has been done on assessment of product approach and process approach, genre-based approach and task-based approach. Unfortunately, finding a satisfying teaching method for college English writing still cannot be achieved.

With the development of psycho-linguistics and artificial intelligence, schema theory has increasingly aroused interest of English teachers. A new field in English writing research thus appeared. Schema refers to a collection of knowledge related to a concept and it contains background knowledge of content, text structure and hierarchical organization of the text. During the writing process, students need to activate their previous schemata stored in their long-term memory and they also have to obtain new knowledge which helps them create good essays. Schemata supply the necessary knowledge of phrases, content and organization forms, which have much influence on writing planning, revising and editing process. Most of the teachers, however just study the relationship between the schema theory and writing, and at best they offer some suggestions about how to improve students' writing ability. As for some quantitative research, teachers just choose one or two classes as subjects in the traditional teaching environment.

With the revolution in communication technology, computers has become increasingly important in English teaching especially in teaching writing, because its open-ended environments supply individuals with tools and materials to develop their own learning habits and the modern technology can offer innovative solutions to problems which cannot be solved in traditional classrooms. Concerning how to enhance students' writing ability with high technology, especially by multi-media technology, researchers in China have made their studies as follows: Yang Yonglin has developed three-dimensional, digital, and open writing practice system; Wang Dong and Zhang Xinhua work on the design of writing teaching system in an website; Liang Maocheng and Wen Qiufang contribute to the automatic rating system of writing, and Wang Lifei studies about writing by using Writer's Workbench. However, doing research in teaching English writing in classrooms with a certain theory is still necessary.

\section{Research Methodology}

\section{A. Research Questions}

This research focuses on a method to teach English writing, namely, the application of schema theory in teaching English writing with the assistance of computers and Internet. To find out whether the schema-oriented teaching method assisted by computers and Internet is effective in improving students' writing ability, the research is carried out to answer the following questions. 
1. What problems exist in students' essays in terms of schema theory?

2. Is the schema-oriented teaching method assisted by CALL effective to solve these problems and to improve students' writing ability?

3. Why this teaching method is effective in improving students' writing ability?

\section{B. Subjects}

The present research involves 60 non-English majors in the experimental class and 60 in the controlled class in Qingdao University of Science and Technology. Students in these two classes come from the same major. 67 male and 53 female students are included respectively. Since the subjects are sophomores, they have already been familiar with the college life after a year and the author finds out many of them are low-proficient in English writing.

\section{Instruments}

The method in the research consists of both qualitative and quantitative analysis, in which experimental research is dominant and descriptive study served as an important supplement. There are four kinds of instruments used in the research: questionnaire, tests, email interview and the Jacob's rating standards.

Questionnaire

The questionnaire is designed to find out what factors affect students' writing ability and their attitudes towards writing. To avoid any misunderstanding of the questions, the questionnaire is presented in Chinese.

\section{Pre-test}

The pre-test is aimed to check students' proficiency in writing before the experiment. All subjects were required to attend the pre-test on 2nd September and they were asked to write an essay entitled "We shouldn't totally turn to Internet" in about 150 words in half an hour.

\section{E. Post-test}

At the end of the semester, the post-test is conducted with the writing task entitled "Opportunity and success", aiming to find out whether students are better at writing and in which aspects they gain improvement.

\section{F. Interview}

The interview is carried out by email to get students' attitudes towards the schema-oriented writing instruction assisted by computers.

\section{G. Rating Standards}

The rating standards used in the research are standards of Jacob et al, 1981, which indicates: content accounts for $30 \%$, organization $20 \%$, vocabulary $20 \%$, language use $25 \%$, and mechanics $5 \%$ (classified as linguistics in the thesis). The author also rates students' essays based on the rating standards of CET.

\section{H. The Teaching Methods in the Research}

The teaching method in the study is schema theory-oriented instruction in the context of CALL. The teacher is committed to improving students' writing ability by the usage of computers and Internet in writing activities. With the assistance of the Internet and computers, students can actively participate in the teaching activities both in and out of class, so the English writing teaching in this thesis not only refers to teacher's teaching in class, but refers to students' self-teaching after class, which extends the traditional meaning of teaching and learning to some extent.

As the research is carried out in the college English writing teaching class, semantic mapping is applied to enrich students' vocabulary and the author makes full use of intensive reading materials to develop students' awareness of English genre. In the meanwhile, more related culture knowledge is shown to students to train their ability to tell the distinctions in culture. A single research procedure lasts for three weeks consisting of the following three steps.

1. Activate students' previous existing schemata

In the first week of the research, the teacher organizes activities to activate students' schemata in the pre-writing stage. The teacher will analyze sample essays by branching and schematic analysis of the structure in order to acquaint students with the structure of English essays, and introduce cultural knowledge by showing video materials and asking open questions. What's more, topics will be given to students to search online for related information and materials after class.

2. Construct new schemata in the composing process

In the second week, the teacher offers the related materials about the topic to students by PowerPoint texts. Students are asked to discuss and verbalize their ideas in pairs or groups. Group discussion and brainstorming are two effective methods to activate their schematic knowledge. After the discussion, students decode information through schema knowledge and write the essay at class. Self-correction and peer-correction are also conducted at class. The author will offer students rating standards to help them correct their classmates' essays and asks students offer some suggestions as well.

3. Consolidate students' schemata by revising essays

In the third week, tutor-feedback and assessments are given. The students email their essays to the teacher after 
self-correction and peer-correction as required, and the teacher revises and rates the texts according to the same rating standards. Samples are chosen for whole-class comment. By using the computer, it is easy for students o participate in correcting samples. Students are asked to refine the text and thus they can further understand the problems in their English writing.

Writing topics are confined to argumentation owing to the time limit. Since one important reason of learning English is to express ideas, argumentation is essential in showing one's ideas. Writing topics in the research are chosen from New Horizon College English (reading and writing, second edition) and from the CET topics. Topics include: we shouldn't totally turn to Internet; the craze of pursuing graduate studies; on the low-carbon life; how to deal with sub-health; opportunity and success.

\section{Data Collection and Analysis}

Samples used in the analysis are chosen based on the following rules: students attend each of the class in the research; students email every requested essay to the teacher. The number of all valid samples is 56 in each class.

All the samples of students from both the experimental and the controlled class in the pre-test and the post-test are rated according to the standards of Jacob Scale of Rating and CET rating scales. To guarantee the objectivity of the assessment, the author grades the samples together with the other teacher who is also a college English teacher. The author and the colleague serve as two raters and the scores the author uses in the analysis are the average of the two scores. After the grading, the author makes a contrast analysis of samples in the pre-test and post-test from the experimental class with the help of SPSS 11.5. The author also makes a contrast analysis with the controlled class to find out whether students are better in writing.

\section{FINDINGS AND DisCUSSIONS}

With the help of multi-media and computers, and the application of schema theory, the research is done successfully. Data is collected and analyzed by SPSS 11.5, and findings are presented in the following part.

\section{A. Data Analysis of the Questionnaire}

A questionnaire is conducted to understand the subjects' writing problems. The following table 4.1 reveals the number of subjects choosing different the answers to each question in the questionnaire, and the following results are presented.

TABLE3.1

THE QUANTITATIVE ANALYSIS OF QUESTIONNAIRE

\begin{tabular}{|l|l|l|l|}
\hline & A & B & C \\
\hline 1 & 0 & 52 & 68 \\
\hline 2 & 73 & 47 & 0 \\
\hline 3 & 79 & 41 & 0 \\
\hline 4 & 81 & 12 & 27 \\
\hline 5 & 29 & 75 & 16 \\
\hline 6 & 62 & 40 & 18 \\
\hline 7 & 20 & 56 & 44 \\
\hline 8 & 48 & 51 & 21 \\
\hline 9 & 21 & 73 & 26 \\
\hline 10 & 25 & 28 & 67 \\
\hline 11 & 83 & 37 & 0 \\
\hline 12 & 23 & 76 & 21 \\
\hline 13 & 39 & 43 & 38 \\
\hline
\end{tabular}

It can be indicated that the following reasons cause the poor performance in English writing: (1) lack of interest, (2) lack of vocabulary and grammar knowledge, (3) lack of knowledge of English text structure, (4) lack of awareness of coherence methods even they have already acquired some, (5) lack of culture background knowledge, (6) lack of revision after writing.

From the above analysis, the conclusion can be drawn that the reasons why students lack interest in English writing is that they do not accumulate adequate vocabulary or textual structure knowledge or proper coherence means to produce an essay. This disadvantage makes them reluctant to read English materials, and in turn, this unwillingness impedes their grasp of relevant culture knowledge for writing, while teachers' instruction plays an important role in improving their writing ability and peers' discussion is also helpful. From this questionnaire, the author decides to adopt the schema theory in the teaching practice and explores an effective way to improve students' writing ability.

\section{B. Data Analysis of the Pre-test and the Post-test}

In the wake of the pre-test and the questionnaire, schema-oriented teaching method is implemented in the writing instruction within a span of 16 weeks.

The analysis of the pre-test and the post-test is aimed to find out whether students in the experimental class are better in writing than those in the controlled class. 
TABLE 3.2

GROUP STATISTICS OF ORGANIZATION SCORES OF TWO CLASSES IN PRE-TEST

\begin{tabular}{|l|l|l|l|l|l|}
\hline & class & $\mathrm{N}$ & Mean & Std. Deviation & Std. Error Mean \\
\hline score & experimental & 56 & 1.4308 & .27648 & .03173 \\
\hline score & controlled & 56 & 1.4975 & .34094 & .04330 \\
\hline
\end{tabular}

TABLE3.3

GROUP STATISTICS OF ORGANIZATION SCORES OF TWO CLASSES IN POST-TEST

\begin{tabular}{|l|l|l|l|l|l|}
\hline \multicolumn{5}{c}{ GROUP STATISTICS OF ORGANIZATION SCORES OF TWO CLASSES IN POST-TEST } \\
\hline score & class & $\mathrm{N}$ & Mean & Std. Deviation & Std. Error Mean \\
\hline score & controlled & 56 & 1.8153 & .25641 & .03214 \\
\hline
\end{tabular}

Table 3.2 reveals the mean and standard deviation for the analytic organization scores of the two classes in the pre-test, while Table 3.3presents date in the post-test. In the pre-test, the mean of the experimental class is 1.4307 with the standard deviation of 0.27648 , while the mean of the controlled is 1.4975 with the standard deviation of 0.34094 . The mean difference of the two classes is 0.0667 , which indicates there is little difference of organization scores in the pre-test. In the post-test, the mean of the experimental class is 1.8153 with the standard deviation of 0.25641 , while the mean of the controlled is 1.5036 with the standard deviation of 0.25873 . The mean difference of the two classes is 0.3027 which is about 4.5 times of that in the pre-test, which indicates students in the experimental class improve a lot in composing the structure of English essays.

TABLE 3.4

GROUP STATISTICS OF LINGUISTIC SCORES OF TWO CLASSES IN PRE-TEST

\begin{tabular}{|l|l|l|l|l|l|}
\hline & class & $\mathrm{N}$ & Mean & Std. Deviation & Std. Error Mean \\
\hline score & experimental & 56 & 3.6703 & .53906 & .06734 \\
\hline score & controlled & 56 & 3.6213 & .38792 & .04913 \\
\hline
\end{tabular}

TABLE 3.5

GROUP STATISTICS OF LINGUISTIC SCORES OF TWO CLASSES IN POST-TEST

\begin{tabular}{|l|l|l|l|l|l|}
\hline & class & $\mathrm{N}$ & Mean & Std. Deviation & Std. Error Mean \\
\hline score & experimental & 60 & 4.1873 & .43464 & .05611 \\
\hline score & controlled & 60 & 3.6667 & .80605 & .10406 \\
\hline
\end{tabular}

Table 3.4 reveals the mean and standard deviation for the analytic linguistic scores of the two classes in the pre-test, while Table 3.5 presents date in the post-test. In the pre-test, the mean of the experimental class is 3.6703 with the standard deviation of 0.53906 , while the mean of the controlled is 3.6213 with the standard deviation of 0.38792 . The mean difference of the two classes is 0.049 , which indicates there is little difference of linguistic scores in the pre-test. In the post-test, the mean of the experimental class is 4.1873 with the standard deviation of 0.43464 , while the mean of the controlled is 3.6667 with the standard deviation of 0.80605 . The mean difference of the two classes is 0.5206 which is about 10 times of that in the pre-test, which indicates students in the experimental class improve a lot in vocabulary when writing English essays.

TABLE 3.6

GROUP STATISTICS OF CONTENT SCORES OF TWO CLASSES IN PRE-TEST

\begin{tabular}{|l|l|l|l|l|l|}
\hline \multicolumn{7}{|c|}{ GROUP STATISTICS OF CONTENT SCORES OF TWO CLASSES IN PRE-TEST } \\
\hline & class & $\mathrm{N}$ & Mean & Std. Deviation & Std. Error Mean \\
\hline score & experimental & 56 & 1.9058 & .18681 & .02316 \\
\hline score & controlled & 56 & 1.9472 & .16592 & .02046 \\
\hline
\end{tabular}

TABLE 3.7

GROUP STATISTICS OF CONTENT SCORES OF TWO CLASSES IN POST-TEST

\begin{tabular}{|l|l|l|l|l|l|}
\multicolumn{9}{c}{ GROUP STATISTICS OF CONTENT SCORES OF TWO CLASSES IN POST-TEST } \\
\hline & class & $\mathrm{N}$ & Mean & Std. Deviation & Std. Error Mean \\
\hline score & experimental & 60 & 2.4407 & .34557 & .04461 \\
\hline score & controlled & 60 & 2.0250 & .55560 & .07173 \\
\hline
\end{tabular}

Table 3.6 reveals the mean and standard deviation for the analytic content scores of the two classes in the pre-test, while Table 3.7 presents date in the post-test. In the pre-test, the mean of the experimental class is 1.9058 with the standard deviation of 0.18681 , while the mean of the controlled is 1.9472 with the standard deviation of 0.16592 . The mean difference of the two classes is 0.0414 , which indicates there is little difference of content scores in the pre-test. In the post-test, the mean of the experimental class is 2.4407 with the standard deviation of 0.34557 , while the mean of the controlled is 2.0250 with the standard deviation of 0.55560 . The mean difference of the two classes is 0.4157 which is about 10 times of that in the pre-test, which indicates students in the experimental class improve a lot in the content when writing English essays.

\section{The Contrast of the Experimental Class in Post-test and Pre-test}


TABLE3.8

PAIRED SAMPLES STATISTICS OF ORGANIZATION

\begin{tabular}{|l|l|l|l|l|l|}
\hline \multicolumn{2}{|c|}{ PAIRED SAMPLES STATISTICS OF ORGANIZATION } \\
\hline \multirow{2}{*}{ Pair 1 } & VAR0001(post) & Mean & N & Std. Deviation & Std. Error Mean \\
\cline { 2 - 6 } & VAR0002(pre) & 1.8140 & 56 & .25620 & .03340 \\
\hline
\end{tabular}

TABLE 3.9

PAIRED SAMPLES STATISTICS OF LINGUISTIC SCORES

\begin{tabular}{|c|c|c|c|c|c|}
\hline & & Mean & $\mathrm{N}$ & Std Deviation & Std Frror Mean \\
\hline \multirow{2}{*}{ Pair 1} & VAR0001(post) & 4.1973 & 56 & .51517 & .07289 \\
\hline & VAR0002(pre) & 3.5723 & 56 & .52916 & .06734 \\
\hline
\end{tabular}

TABLE 3.10

PAIRED SAMPLES STATISTICS OF CONTENT SCORES

\begin{tabular}{|l|l|l|l|l|l|}
\hline \multicolumn{2}{|c|}{} & Mean & N & Std. Deviation & Std. Error Mean \\
\hline \multirow{2}{*}{ Pair 1 } & VAR0001(post) & 2.4307 & 56 & .19473 & .05128 \\
\cline { 2 - 6 } & VAR0002(pre) & 1.9057 & 56 & .27691 & .02316 \\
\hline
\end{tabular}

From the analysis above, it can be concluded that the empirical study has achieved a significant success. The analysis of questionnaire and the pre-test proves that lexical schematic problems, syntactic and textual problems do exist in students' essays. Thus, the schema theory is adopted in the empirical study, and computers and the Internet is applied to teach college English writing. After a span of 16 weeks, the author finds that students in the experimental class get much higher scores in the post-test than in the pre-test. Their essays are much better in the aspect of organization, linguistic and content, which matches the analysis of paired samples t-tests. Therefore, from the data in this part, the teaching method under discussion is effective to improve students' writing proficiency.

\section{The Analysis of the Email Interview}

In order to find out students' attitudes towards the schema-oriented writing instruction assisted by computers, the email interview is conducted since students are busy at the end of the semester. The interview lasted for a week, and all the 56 students from the experimental class took part in it. The author catalogues the students into three groups: high-level group, intermediate-level group and low-level group. Six questions were talked about as follows:

(1) Do you think your writing ability is improved after the semester? If it is, in which aspects?

(2) Do you think it is important to explain some relevant culture and background knowledge in the pre-writing phase?

(3) In the revising phase, do you like peer feedbacks?

(4) If your essay is chosen to be the sample for whole-class revising, will you feel stressed?

(5) Do you rewrite your compositions after revision?

(6) Do you have any suggestions for teaching English writing?

After analyzing the students' answers, the conclusion can be drawn that students hold positive attitudes towards this teaching method, and virtually they have made great progress in their English writing. Firstly, with the help of computers and the Internet, a friendly learning environment is set up in which students can interact with teachers easily. Secondly, the interesting activities in the writing class can arouse students' interest in writing. Thirdly, original teaching methods like new revising methods, new writing habits and thinking patterns, and massive materials used in teaching are essential in composing good essays.

As for the negative sides, the teacher believes it is partly due to students learning motivation or strategies, since they are reluctant to re-write and re-read their essays and it is hard to change their previous writing habits and thinking patterns in a short period. It is worth noticing and paying more attention to them in teaching.

\section{CONCLUSions}

From the results and analysis above, it is clear that students make great improvement in their English writing after experiencing the schema-oriented instruction and many factors can account for the obvious change.

\section{A. Enrich Students'Schemata}

Students' schemata can be built and enriched continuously, since schemata change moment by moment when new information is received. In this teaching study, group discussing, materials searching, ideas sharing, semantic mapping, brain storming even the teacher's and peers' feedbacks can modify students existing schemata, which is vital in improving students' writing ability. Schema theory points out that prior knowledge is packaged into organized structure but it is not only a storage unit for data, it is also a dynamic, flexible, and ever-changing resource of prior knowledge and experiences. In class, the teacher provides many fixed phrases and uses semantic mapping to enrich students' vocabulary, which enlarges students' linguistic schema. Through their searching new materials online and intensive reading, students read more English articles. As a result, this reading acquaints students with more culture related information, which expands their horizon and enriches their content schema. When it comes to formal schemata, the teacher analyzes many structures make students familiar with English essays' organization and the characteristics of 
different genres. In the meanwhile, teacher offers many coherence phrases, which are helpful in making their essays more coherent.

\section{B. Combine Content Schema, Linguistic Schema and Formal Schema}

Schemata can be divided into various kinds and contain various kinds of schema, however, in writing, all the schemata should be integrated since it is a complex process. That is, in writing, linguistic schema, content schema and formal schema should be combined to work.

In this study, during the pre-writing period, students were asked to search materials online and try to understand the materials and the culture differences. As a result, students' content schema is enriched. In the planning period, semantic mapping and brainstorming is adopted to enrich students' linguistic schema. The author also focused on the comparison and contrast of the structures of English and Chinese essays in order to set up and activate students' formal schema. According to the qualitative and quantitative analysis of the research, we can see that students make great improvement in their writing, which means the combination of all these schemata is helpful and effective in enhancing students' writing ability.

\section{Pay More Attention to the Cognitive Writing Process}

In writing teaching, schema theory is the one paying much attention to students' writing cognitive process. Writing begins with observation, which means the writer notices something and is willing to write about it. Writing involves description, which means the writer has to present concrete details with his own words. Writing also relates to finding common links between things and explaining those links. Writers select the type of thinking to focus on in their writing unconsciously and their way of observing, thinking, recording, and structuring may alter from situation to situation. In a word, writing is a thinking process unique to each individual.

Schema theory focuses on cognitive processes and serves as guidance in teaching. In the research, students' thoughts are dug out by brainstorming. Students have the chance to express their ideas freely, which is good to restore and activate their existing schemata. Through peer revision, students get more chance to use their schemata and modify their existing schemata sometimes, because the student raters have to interpret the information from their classmates' essays and judge if that information is right. If they lack such corresponding schemata, they will turn to dictionaries so that to enrich their existing schemata. Therefore, the schema-oriented instruction assisted by computers and the Internet can strengthen students' awareness of writing process.

\section{Improve Students ' Competence in Information Processing}

Writing is a cognitive process in which students have to understand what to write and how to write. During this process, finding ways to restore the previous knowledge and enriching their knowledge is essential, which means teachers need to activate students' schemata. The schema-oriented instruction used in this study may help students activate their schemata and guide them in processing information. Though teachers apply different activities in different periods in writing, which does not mean writing can be divided into parts. On the contrary, it is an integrated process and students need to understand this point. Likewise, different schemata are introduced and enriched respectively at class, which does not mean they can be independent from each other. On the contrary, the schemata can be operated interactively to make a qualified writing. Therefore, activities in the pre-writing phase can improve students' cognitive ability in understanding what to write and how to write.

\section{REFERENCES}

[1] Chang Zonglin. (2005). Cognitive Studies in Language \& Culture. Qingdao: China Ocean University Press.

[2] Chang Zonglin. (2002). Schema and its Function. Shandong Foreign Language Teaching Journal, 5, 27-30.

[3] Chen Hong. (2009). The Design Conception and Theoretical Basis of the University English Writing Teaching Auxiliary Platform. Foreign Language World, 1, 78-85.

[4] Hofstede G. (1994). Cultures and Organizations: software of the mind. London: Harper Collins.

[5] Howard, R.W. (1987). Concept and Schemata: an introduction. London: Cassel Educational.

[6] Li Mingyuan. (2001). The Schema Theory and English Writing. Journal of Sichuan International Studies University, 4, 77-79.

[7] Liang Maocheng \& Wen Qiufang. (2007). Review and Inspiration of Foreign Automatic Scoring System for English Writing. Computer-assisted Foreign Language Education, 5, 18-24.

[8] Rumelhart, D. E. (1980). Schemata: The Building Blocks of Cognition. NJ: Lawrence Erlbaum Associates.

[9] Saad Al-Kahtani. (2009). Computer Assisted Language Learning. Saarbrücken: VDM Publishing.

[10] Wang Dong \& Zhang Xinhua. (2004). The Instruction System Design of the Subject Website for College English Writing. Computer-assisted Foreign Language Education, 3, 29-32.

[11] Wang Lifei. (2011). Computer-aided Second Language Research Methods and Their Applications. Beijing: Foreign Language Teaching and Research Press.

[12] Wang Wenyu \& Wang Lifei. (2004). The Review and Prospect of Second Language Writing for the Last Ten Years. Foreign Language World, 3, 51-58.

[13] Yang Yonglin. (2005). Research Development Made Easy - A Computer-based Design System for Academic Writing. Beijing: Higher Education Press.

[14] Yao Lan \& Cheng Lini. (2005). A Review of Research on EFL writing in China from 1980s. Foreign Language World, 5, $2-9$. 
Fushan Sun was born in Qingdao, China in 1977. She received her M.A. in linguistics from Ocean University, China, in 2009. She is currently a lecturer in the School of Foreign Languages, Qingdao University of Science and Technology, Qingdao, China. Her research interests include second language acquisition and cross-cultural communication. 